\title{
Study on the Regional Pattern Selection of Ecological Migration in the Loess Plateau
}

\author{
Xuexue Bai, Aiguo Zhang* \\ School of Geographical Sciences, Shanxi Normal University, Linfen, China \\ Email: $\underline{\text { 348951835@qq.com }}$
}

Received 16 June 2015; accepted 13 July 2015; published 16 July 2015

Copyright (C) 2015 by authors and Scientific Research Publishing Inc.

This work is licensed under the Creative Commons Attribution International License (CC BY). http://creativecommons.org/licenses/by/4.0/

(c) (7) Open Access

\section{Abstract}

The choice of the immigrant regional pattern will decide the success or failure of the ecological migration in a certain degree. According to different administrative scopes of the migration, scholars divided the ecological migration into different regional patterns, but the scholars had different views on the pros and cons of various models. Taking the Loess Plateau as an example in this paper, the author selected four typical case zones: village relocation, township relocation, county relocation, and trans-country relocation. By analyzing them one by one, the paper sums up the characteristics of the four patterns. The probe into the regional pattern of ecological migration in the Loess Plateau helps the author sum up the problem in choosing of regional mode. In the end, the choice of the future regional pattern of ecological migration in the Loess Plateau has been discussed, which will provide the decision-making basis for the future ecological migration in the Loess Plateau.

\section{Keywords}

Ecological Migration, Regional Pattern, Loess Plateau

\section{Introduction}

The immediate cause of the first ecological migration is the poverty alleviation. With the deterioration of the ecological environment, people began to get a deep understanding about the relationship between man and nature, and the practice of ecological migration spreads widely throughout the country. As a result, the study of ecological migration in the academic circle is also followed up [1]. Therefore, ecological migration is not only a process of environmental protection and improvement, but also an effective mean to alleviate poverty and promote regional urbanization development. The Loess Plateau area is not only one of the main impoverished re-

${ }^{*}$ Corresponding author. 
gions in China, but also one of the areas where substantial environment is harsh and fragile with various kinds of environment pollution. What's more, for nearly thirty years, ecological migration here has been typical in both scale and features, and this area is one of the best places for the research of ecological migration in China [2]. And the choice of the migration regional pattern plays a decisive role in the success of the ecological migration. The article studies and summarizes the regional pattern choice of ecological migration in the Loess Plateau, through the analysis of the survey data of the immigrants from Shanxi, Shaanxi and Ningxia. The regional patterns of ecological migration in the Loess Plateau were divided into four types: village relocation, township relocation, county relocation, and trans-country relocation.

There are many studies on the regional pattern of ecological migration in the existing literature, but the scholars have different views on the pros and cons of various models. Liu Xuemin and Chen Jing (2002) favored the immigration form of the small dispersive immigration in the native township and the home village, not engaging in trans-county migration, and believed the former has a small investment and instant gratification [3]. Fang Bing and Peng Zhiguang (2002) proposed the idea of immigrating from the two plateau (the Loess Plateau and the Yunnan-Guizhou Plateau) to the two plain (the Northeast China Plain and the Yangtze Plain, Middle and Lower) [4]. Wu Ligeng (2007) deemed that the immigration vision should not be constrained by the principle "the nearest handy", but should be expanded to the country [5]. Zhang Yunyan (2011) thought that the development mode has both advantages and disadvantages, but no matter which model is selected, the ecological environment of the origin area can be significantly improved; the carrying capacity of the land and water resources of the immigrant areas should adapt to the population sizes, and get sustainable development [6]. The Loess Plateau region involves a wide range and variety of types, and thus we should take the factors of all aspects into consideration and select the local mode in a scientific and reasonable way.

At present, the Loess Plateau region models in village relocation, the relocation within the township supplement, and relocation range are small. However, with economic and social development, as well as the increasing demand for poverty alleviation and ecological environment, the government should adopt policy regulation to change the regional mode of migration into a wider range. Through the research on the current regional pattern of the Loess Plateau, the research is to provide a theoretical basis for the government to formulate the macro policy of the relocation of the immigrants.

\section{Regional Pattern of Ecological Migration in the Loess Plateau}

The regional pattern of the migrated village at present informs that the Loess Plateau relocation to the regional model based mainly in the village relocation, and the relocation within the township supplement, the relocation of county and the trans country are relatively small. This thesis selects four typical villages of Shanxi, Shaanxi and Ningxia provinces in the Loess Plateau and makes research on them respectively.

\subsection{Village Relocation}

2.1.1. Typical Case Analysis_Checheng Village in Checheng Town of Jixian County Shanxi Province Located in the eastern outskirts of the Jixian county and adjacent to 309 National Road, Checheng village expands to the east area of the county, and is the gateway to the land of the county. The administrative village now belongs to immigrant village, and the immigration sources relates to 8 villages, which have distances of 1 - 10 kilometers ranging. Relocation aid departments is the Poverty Alleviation Office, and the sources of funding is special funds. The financing for the relocation of households is allocated according to the number of people. The first batch is in 2002-2003, and the total subsidy for each person is 1500 Yuan, but the real subsidy is 800 Yuan/ person by excluding public infrastructure; the second batch is in 2006, and the total subsidy is 3000 Yuan/person; the third is in 2008, with subsidies 3400 Yuan/person. Before the relocation, the per capital net income of immigrants is less than 1000 Yuan/person, but now the income is 3567 Yuan/person. The source of income is mainly apple, corn, walnut. There are merely a small number of villagers working outside for a long term, and most of villagers choose to work outside for a short time.

After the relocation, infrastructure facilities have been improved, and the transportation, water, and electricity facilities are good in condition. In 2010, it only took more than ten minutes to get to the county by bus; after the relocation, the daily water for immigrants is tap water, the village has a sewer. The bath, toilet conditions of migrants have also been improved. But each natural village have a school before the relocation, children spent only ten minutes going to school, but there is only one school in Checheng country now, and most children choose to 
go to Checheng for study, and the distance is much longer than before. Although the living condition after the relocation is much better, but the yard is small and there is no storage place for farm tools and no vegetable garden.

\subsubsection{Basic Form and Feature Analysis}

The regional model depends on and makes full use of the original village infrastructure and land resources. Under the village government unified coordination and arrangement of land, residents who lived in the poor living environment and production conditions have migrated to the native village where the natural condition is well and of great potent for development [7].

The characteristic of this region pattern is that the space displacement is small and the cost is low; the area of the old village homestead is not changed, and the old village has the homestead right certificate, and was released by new village. The relocation has no effect on farming mode of operation; the total area of the village and per capital arable land have no change whether it is before or after the relocation; after the relocation, the village cadres and the masses has a good relationship, which is good for unified management; the production and lifestyle of the immigrants have no change and the adaptability is good after the migration. However, after the removal, the original old homestead and arable land still belong to themselves, it will become "migratory bird"; in this regional pattern, the distance is short, and the natural environment of the home vegetation, the amount of the wild animals, and the soil erosion cannot be improved.

\subsection{The Relocation of Township}

\subsubsection{Typical Case Analysis-Wali Village in Zhangdian Town of Pinglu County Shanxi Province}

Wali, a new village of immigration, located one kilometer away from north of Zhangdian Town, and immigrants there came from 3 three natural villages of this administrative village, and other administrative villages in Zhangdian town: Shuimogou, Gaojiazhuang, Guojiazhuang of Gucheng administrative village, Tingli of Hengjian administrative village, Nanwa, Litiegou of Zaoyuan administrative village etc, from the new immigration village $2-10 \mathrm{~km}$ range, the relocation of migrants in these villages in 2006. The financing for the relocation of households is allocated according to the number of people. Before the relocation, the per capital net income of immigrants is less than 1000 Yuan/person, now there is more than one way to raise money, a month of pure income is 1000 Yuan. The source of income is mainly engaged in transportation, work, species tomatoes, aquaculture, of which engage in transport accounted for $35 \%$, work for $25 \%$, the kind of tomato for $15 \%$, aquaculture accounted for about $25 \%$. Contracted land is the natural village as the unit to carry on the ground, the relocation does not affect the arable land (forest land) quantity and quality of all the villagers in natural village. Village homestead accounted for 101 acres forest land of town, 11,000 Yuan per-acre, and flat fee 500 Yuan/household. Village has individual enterprise, the scale of the aquaculture industry, the village of "one village one product" is sheep.

After the relocation, the public facilities projects were organized and implemented by the township, and water, electricity, road and other infrastructure facilities have been basically achieved; after the relocation, the living water for immigrants is tap water, and there are sewer as well. The living conditions have been improved; now, the migrant's electricity is relatively stable, except for the annual overhaul time. Generally it is not blackout; there are 3530 meters of new built circuit, hardened roadway, complete green area of 1800 square meters, as the whole village moved to the town government station, the bus is very convenient. Now it only takes $2-3$ minutes to walk to the Township Center, and less than 30 minutes to the county when driving cars.

\subsubsection{Basic Form and Feature Analysis}

This relocation of township is due to the poor ecological environment and is lack of infrastructure and resources for immigration in the native village, so they are areas that take full advantage and rely on the township's infrastructure and arable land resource. Its basic form is, arrange the expropriated or leased land from the government in the area to the resettlement of farmers, then the relevant organizations and departments of the government will make unified planning, unified organization and implementation. The population and village are relatively concentrating after migration, the moving infrastructure and service facilities are relatively complete [7].

The characteristic of this region pattern is that the relocation has no effect on tillage management, the family income increases, and the economic production of the immigrant has better adaptability; this model is convenient for the management and coordination, the villagers' ideas, culture, values and religion are similar, so the 
living environment of immigrants is also of better adaptability. The total cultivated land and per capital cultivated land area of the village before and after the relocation did not change, and immigrant farming is not easy; after the relocation, immigrants' living expenses increased and after the relocation, they still follow the original mode of production and way of life, and the pressure on the ecological environment of the moving continue to increase. Within a relative long period, the environmental degradation of the moving could be caused [8].

\subsection{County Relocation}

\subsubsection{Typical Case Analysis-Hongdunliang Village in Hequan Town of Dingbian County Shaanxi Province}

Hongdunliang village of immigration is located in Hequan town, 8 kilometers west of Dingbian county, Shaanxi province. It consisted of disperse households of Baiyu Mountain Areas in Dingbian County, and the regional mode is the relocation of the county. In 2004, 300 household, about 1250 people moved out, and the distance of the old village from the village has a dozen kilometers ranging. Because of economic reasons, poor households in the village reluctant to move. The relocation aid departments is the Poverty Alleviation Office, the sources of funding is special funds, and the poor households below 2500 Yuan per capital in Baiyu Mountain Area are qualified to get the money, the combination of household finance and farmers' self financing, each household is going to pay 23,414 Yuan, each household has complete facilities, such as a single yard, three west rooms, and 13 acres of irrigated land. The project was organized by the Poverty Alleviation Office. Homestead Village is bought by the Poverty Alleviation Office with the old land of Yanchangbao and Hongdunliang by 205 Yuan peracre. Farmers are free from them. The relocation has effect on tillage management: dry land turned into irrigated fields, it increased the yield, and the actual land quality is not good. Migrant villagers have an income of per capital 15,000 - 20,000 Yuan, the main source of income is from crop farming (20\%), working (70\%), and aquaculture (10\%). The total number of long-term working outside the village is more than 120 people, accounting for $10 \%$ of the total number; the main work area is the Dingbian County, and most of villagers engaged in the construction industry and technology.

The living condition and environment in Baiyu Mountain Area is poor-environmental degradation, drought and water shortage, a large population with relatively little arable, barren land, live at the mercy of the elements, frequent natural disasters (collapse, debris flow); living conditions were improved after removal, and there is a school, a health center, power supply normal; migrant living water is the tap water, no charge for water; irrigation water for groundwater, there is a sewer, individual families have solar energy. Immigration village to the county 7 kilometers, 8 kilometers to the town, there are taxis and passing cars, no buses; no public baths, the toilet is still dry toilet; before and after the relocation, the relationship between village cadres and the masses is not harmonious.

\subsubsection{Basic Form and Feature Analysis}

For this immigration mode, the number of immigrants is large; the environment of the natural township is too bad and the land resources are limited, in-situ placement is difficult; county government made overall planning about the implementation of the county (inter township) relocation. County government coordinated the township that have better environmental conditions and adequate resources, and solved the problem of relocation land in county through requisition or paid transfer [7].

The characteristic of this region pattern is that the production and living conditions of immigrants has been greatly improved after the relocation, what's more, the household income increased significantly, tillage management has changed, the source of income increased, the transport, communications and other infrastructure better immigration, closer to the county, to facilitate immigration of migrant work, and the number of people engaged in the two or three industry is increased. Centralized resettlement for immigration has promoted the intensive use of resources and infrastructure, the ecological environment of the original place of residence has also been improved, reached the basic effect of ecological migrants. However, the immigration model is based on the county wide range of suitable for the relocation of the surplus land, but now that is not much.

\subsection{Trans-Country Relocation}

\subsubsection{Typical Case Analysis—Laochi Village in Xingjing Town of Yinchuan Ningxia}

Laochi village, located in northeast edge of Xingjing town, Xixia District of Yinchuan City, covers an area of 
4603.1 acres. There are 610 households and 2875 spontaneous immigrants, and most of them came from Haiyuan County, Tongxin County, the Hui population accounted for 95\% of the total population. For the convenience of management, Xingjing town Party committee and government set up a comprehensive management immigration station at here in June 2005, and established the Mobile Party Branch in August 5, 2008 [9]. After the removal near the Yinchuan city, immigrants can easily go out to work, which increases the immigration income; $96 \%$ of the immigrant has communications equipment after the relocation, some people already own a mobile phone, also has landline and computer; $74 \%$ of the immigrant family have garbage dumps, above 1/3 of the immigrant families have sanitary toilets.

$100 \%$ of the migrant water from the "well water"-"hand pressure well”; the village has a kindergarten, primary school, medical point, it is convenient for people to go to school, and take medical care; the year round power reached more than $90 \%$, some people use as a pretext electricity(not apply alone, through the electric meter of others), Some people make use of private pull wire to meet their electricity demand; because of the confusion of residential staff and electricity management, the phenomenon of electricity theft exists, which improves the cost of electricity; the village has no garbage disposal point, no public toilet; the traffic conditions is poor, lacking of hardening. The hygiene condition is also poor, too narrow; immigrants of Laochi village came from different area, and it has a complex personnel, population movements frequently. As long as people have no great conflicts, they can live in peace and harmony. Communication there is not close, and most of the immigrants think that the neighborhood is general, but social security is poor.

\subsubsection{Basic Form and Feature Analysis}

This geographical pattern of the relocation of immigrants has a long distance, original residence and its surrounding areas mountain reclamation is serious, it has vegetation damage and serious soil erosion. The ecological environment is quite bad, and the economic strength of the moving region is stronger, and has the advantage of natural and location conditions. Therefore, the provincial or municipal government makes co-ordinate planning and implement of Cross County relocation to resolve land issues with paid allocation and other forms.

The characteristic of this region pattern is that the migration of immigrants from long distance reduces the pressure on the ecological environment of the original residence, and the living conditions of the immigrants have been improved, achieving the poverty and ecological construction of the "win-win". This model organically combines the ecological improvement of the original residence, the poverty alleviation project and the development of the moving land, has achieved the effectiveness of improving the environment, poverty alleviation and regional economic development, producing a great economic, social and ecological benefits [10]. But the distance of this relocation mode is far, after the relocation, immigrants moving to the new residence have difficulty in the production, live, psychology and other problems, which will affect the immigration satisfaction and the moving-back phenomenon may occur, or the emergence of new poverty issues may emerge.

\section{Problems in the Regional Pattern Selection of Ecological Migration in the Loess Plateau}

\subsection{Moving Distance Is Too Near}

The main regional pattern of the Loess Plateau is within the village and township relocation, and the migration distance is very near, many residents moved to a place which is of only 0.5 kilometers away from the original residence. Immigrants can only work as an emergency measure, the production and life still affect the original residence, which will not fundamentally alleviate the contradiction between the population and resources environment of the original residence, so the ecological environment of the moving is not improved. And the local immigration is difficult, the consolidation rate is low, the enthusiasm of immigrants is not high.

\subsection{Low Level of Urbanization of Immigration}

The level of urbanization in the Loess Plateau is general lower, mainly including the village and township relocation. Most of the migrants are still in the countryside after the relocation, the rural population is high, the urbanization level is low; after the relocation, there are few buildings setting up, and large public infrastructure is still imperfect etc., low level of Land Urbanization; most of the migrants still live in the village after the move, so they mainly engaged in farming and animal husbandry, even the two or three industry is mainly focused in 
the technology requirements of the lower labor intensive industries; many immigration points have no industry advantage, geographical advantages, technological advantages and talent advantages, low level of agricultural modernization development, the lack of economic and employment opportunities makes the traditional tillage technology still failed to change, and can only make the majority of immigrants living from the surrounding natural environment for food, fuel, housing materials and other necessities of life; after the relocation, the migrant endowment insurance, medical treatment, employment security, education and other social security system are imperfect.

\subsection{Immigrants Have No Option for Regional Mode}

According to the survey, over ninety percent of immigrants have no right to choose for the regional model, or is their choice, there are no government subsidies. Therefore, the voluntary of the immigrants is poor, and after the relocation of immigrants prone to government dependence on psychology; in addition, part of the immigrants due to the high cost of relocation, not afford, will give up the relocation or emergence of the new poor households after the relocation. And for the county and trans county relocation, the old man has a poor adaptability, not easy to accept the new environment, the rate of return is higher. Cannot reach the expected effect of implementation of relocation.

\section{Investigation on the Regional Pattern of Future Ecological Migration in the Loess Plateau}

\subsection{Adaptation to Local Condition, Reasonable Choice of Regional Mode}

Adjust the current "local resettlement" of immigration policy. Considering the natural conditions, land use condition, environment capacity, economic development and different customs of all nationalities in the Loess Plateau, meanwhile, the advantages and disadvantages of various relocation mode vary, therefore, we should not adopt the relocation mode of "one-size-fits-all". According to the actual situation, the district should choose the reasonable relocation mode, even the same district should consider the differences among farmers, adapts to local condition and explore positively, and constantly optimize the regional model; we should also formulate the implementation plan reasonably, and provide the best model for the immigrants, and make the best of the immigration benefit. Under the premise of local conditions, we should encourage farmers and herders as much as possible to choose county relocation or even the trans-county relocation area model. Therefore, the factors must be comprehensively analyzed in the course of the decision to move, and diversified regional mode should be adopted, and we should choose the distance as far as possible within the county and trans county regional model.

\subsection{Accelerate the Pace of Urbanization}

An effective way to protect the ecological and migration from poverty is to accelerate the pace of urbanization, and promote the immigration process of citizenship. The urban migration has two methods: "a step in place" (immigration directly into the town) and "step by step" (immigrants firstly moved to other natural village, the administrative village or township center, then migrate to the town center). "Step in place" works better than the "step by step" in the long-term development of the immigrants income, infrastructure, social security facilities. Therefore, the government should encourage immigrants to migrant directly into the town. More specifically, guide and gather the immigrant population to the neighboring region of the market and town, meanwhile, government should allow the conditional immigrant population transfer to the towns. For immigrants who have certain market economy consciousness and conditions or labor for living skills, state and local governments should make policies of development of preferential in order to encourage their self-employed placement and accelerate the construction and development of urbanization [11]. At present, most of the towns in the Loess Plateau are not only small, but also take the administrative function as the main function, thus its absorption and radiation ability as the economic center is also very limited. Ecological immigrants require that the towns should not only work as an administrative center, but also bear the function of the economic growth, and provide support for population employment, industry development, urban and rural communication and market cultivation. We should cultivate the labor-intensive industry and trade circulation in the urban construction, and give full play to its role in the communication of the city and countryside elements, industrial contact and market contact [12]. It can be said that the ecological migration is an important opportunity and practice of urbanization, by which the 
structure of population spatial distribution can be adjusted effectively. Therefore, the urbanization of the ecological migrants is of great significance for the change of the ecological environment and the sustainable development of the economy and society [13].

\subsection{Expand the Decision-Making Power of the Villagers' Choice for the Relocation of the Regional Mode}

In the process of ecological migration, governments at all levels should listen to the voices of immigrants, and understand the adaptation situation after the relocation of immigrants and address the difficulties encountered immigration. For immigration concerns, the government should take the relevant measures in time to ensure that the immigrants can live in peace and stability in the moving place. By relaxing the immigration policy, immigrants can choose their own relocation regional model in the premise of reasonable choice of regional mode. For the elderly of poor adaptability, they can choose the village relocation or township relocation that close to original residence. The government should publicize the environmental protection knowledge and make it personally involved in the protection of local ecological environment; for the immigrants who want to enter the city or have certain market economic consciousness and condition, the immigrants who have the skills to earn a living can choose the long-range regional pattern such as county or trans county relocation. The government should provide employment information, production technology training, vocational skills training for these immigrants, and increase the employment channels and family income of migrant. In the face of natural risks and economic risks in the process of migration, the government should establish a sound social security system for immigration.

\section{Conclusion}

Based on the research of the regional pattern of migration in the Loess Plateau, this paper summarizes the existing problems: too near moving distance, the village and township relocation, low level of urbanization, low concentration of population, low land, production and living level of urbanization. Immigrants have no option for regional mode, leading to the immigrants' poor voluntary and adaption. Therefore, we should adjust the "local resettlement" policy in current immigration policy. According to the actual situation in the Loess Plateau and reasonable choice of regional mode, the relocation mode of "one-size-fits-all" cannot be adopted. Government should encourage immigrants to move directly into the town, and accelerate the pace of urbanization. In the process of ecological migration, governments at all levels should listen to the voices of immigrants, and expand the decision-making power of the villagers' choice for the relocation of the regional mode.

\section{Fund Project}

National Social Science Foundation Program "Study on the sustainable development of large scale eco migration in poor areas" (No: 12BJL076).

\section{References}

[1] Pi, H.-F. and Wu, Z.-Y. (2008) A Review of Ecological Immigration Studies in Recent Years. Journal of China Three Gorges University (Humanities and Social Sciences), 30, 14-17.

[2] Zhang, A.G. and Xue, L.-Y. (2013) Ecological Migration Theory in the Loess Plateau. China Social Press, Beijing.

[3] Liu, X.-M. and Chen, J. (2002) Ecological Migration, Urbanization and Industry Development-Investigation and Consideration of Urbanization in Northwest China. Research on Socialism with Chinese Characteristics, 2, 61-63.

[4] Fang, B. and Peng, Z.-G. (2002) Ecological Immigration: New Ideas for the Overcome Poverty and Protection of Environment in West China. Guangxi People’s Press, Nannin.

[5] Wu, L.-G. (2007) Ecological Immigration of Ethnic Minority Regions of Western China on Inter Provincial Resettlement and Ecological Depopulated Zone Delineation of the Problem. Guizhou Ethnic Studies, 27, 47-53.

[6] Zhang, Y.-Y. (2011) Analysis of the Ecological Migration Patterns in the Ethnic Regions-A Case Study of the Ningxia Hui Autonomous Region. Anhui Agricultural Science, 39, 20152-20154.

[7] Li, W.-M. and Jin, D.-Y. (2008) Analysis and Empirical Study on the Resettlement Mode of Aid the Poor Emigration-A Case Study of Rui'an City, Zhejiang Province. Economic Geography, 28, 205-208.

[8] Li, J. (2007) The Resettlement Mode of Ecological Migrants in the Hengduan Mountain Area of Guizhou. Sichuan Na- 
tionality Research, 27, 64-67.

[9] Fan, J.-R. (2012) Comparative Study on the Embedded Spontaneous Immigrant Community in the Hui Nationality of the Ecological Migrants in Ningxia. 2012 Social School Year in China Social Construction Theory Innovation and Policy Design Papers Set, 1-18.

[10] Cheng, Z.-X. and Qin, H.-G. (1999) The Beneficial Analysis on the "Diaozhuang” Villages for Immigrants in Ningxia. Journal of Ningxia University (Natural Science Edition), 20, 92-96.

[11] Liang, F.-Q. (2011) Research on Chinese Ecological Immigration. Journal of China Three Gorges University (Humanities and Social Sciences), 33, 11-15.

[12] Li, Y.S., Xu, F. and Li, X. (2012) Research on Sustainable Development of Ecological Migrants in Ningxia. Ningxia Social Sciences, 1, 29-35.

[13] Suo, D.-Z. and San, J.Y. (2009) Ecological Migrants' Resettlement and Adaptability of Urbanization. Journal of Qinghai University for Nationalities (Social Science Edition), 35, 75-80. 